Saudi Journal of Oral and Dental Research

Abbreviated Key Title: Saudi J Oral Dent Res

ISSN 2518-1300 (Print) |ISSN 2518-1297 (Online)

Scholars Middle East Publishers, Dubai, United Arab Emirates

Journal homepage: http://scholarsmepub.com/sjodr/

Review Article

\title{
Condition and Management: Emergeny in Maxillofacial Trauma- A Review
}

Dr. S. Sandeep ${ }^{1 *}$, Dr. Shreya Jawalkar ${ }^{2}$

1Sr. Lecturer, Dept of Oral and Maxillofacial Surgery, C.K.S. Theja Institute of Dental Sciences and Research, Tirupati Andhra Pradesh India 2Post graduate student, Dept of Oral and Maxillofacial Surgery, C.K.S. Theja Institute of Dental Sciences and Research, Tirupati Andhra Pradesh India

DOI: $10.36348 /$ sjodr.2019.v04i12.009

| Received: 01.12.2019 | Accepted: 09.12.2019 | Published: 22.12.2019

*Corresponding author: Dr. S. Sandeep

Abstract

Facial trauma, with or without life- and sight-threatening complications, may arise following isolated injury, or it may be associated with significant injuries elsewhere. Trauma management has evolved significantly in the past few decades thereby reducing mortality in the golden hour. However, challenges remain, and one such area is maxillofacial injuries in a polytrauma patient. A systematic review of the literature was undertaken to formulate an evidence-based approach to the treatment of life-threatening maxillofacial trauma. This review article aims to provide a concise, contemporary guide for the knowledge about complications and treatment of maxillofacial trauma in the emergency setting.

Keywords: Management, Emergeny, Maxillofacial Trauma.

Copyright @ 2019: This is an open-access article distributed under the terms of the Creative Commons Attribution license which permits unrestricted use, distribution, and reproduction in any medium for non-commercial use (NonCommercial, or CC-BY-NC) provided the original author and source are credited.

\section{INTRODUCTION}

Trauma is a major health and social issue around the world. The incidence and epidemiological causes of maxillofacial (MF) trauma and facial fractures varies widely in different regions of the world due to social, economic, cultural consequences, awareness of traffic regulations and alcohol consumption.

Every year, hundreds of thousands of people of all ages sustain facial injuries from automobile and other vehicular collisions, firearms, athletic activities, or altercations.

The result may be soft tissue damage to the ears, scalp, and face. Many of these injuries are maxillofacial fractures, such as fractures of the lower jaw, upper jaw, palate, cheekbones, nose, and bone surrounding the eyes, skull, or combination injuries. Moreover, injuries to the teeth and supporting structures may result.

Maxillofacial injuries may result in lifethreatening complications and significant cosmetic or functional problems, such as abnormalities in mastication, swallowing, breathing, smelling, and vision. The patient may have chronic pain, and those with extensive residual defects frequently develop psychosocial disorders.
In many countries, the American College of Surgeons Advanced Trauma Life Support (ATLS) system of care is now generally accepted as the gold standard in the management of the injured patient [1].

Fifty per cent of maxillofacial injuries are secondary to assault and fifty per cent of those will have raised alcohol levels. However, it is important to remember that confusion may be secondary to head injury and/or hypoxia so does not assume the patient is drowsy because of alcohol. There is a $10-15 \%$ chance of cervical spine injury in an unconscious patient with severe maxillofacial trauma.

Maxillofacial injuries may occur in isolation, although they are commonly associated with concomitant injuries elsewhere [2-4]. Injuries above the clavicles may initially appear to be minor but can quickly deteriorate and become life or sight threatening [5].

\section{Trauma trimodal distribution}

Deaths following trauma follow a trimodal distribution. The first peak, at the scene within seconds or minutes of the injury, deaths generally result from lacerations of the brain, brain stem, high spinal cord, heart, aorta and other large blood vessels. Very few of these patients survive because of the severity of their injuries. Only prevention can significantly reduce this peak of trauma-related deaths. The second peak 
constitutes those patients who arrive alive in the resuscitation room but who succumb to their injuries within minutes or hours. Deaths in this stage are usually due to severe chest injuries with hemothorax or cardiac tamponade, abdominal trauma with ruptured spleen or lacerations of the liver, or fractures, particularly pelvic and/or other multiple fractures associated with significant blood loss. The third peak represents patients who succumb days or even weeks later from causes such as multiple organ failure, respiratory distress or sepsis. Care provided during each of the preceding periods impacts on patient outcome during this stage.

\section{Advanced trauma life support for maxillofacial injuries:}

Although the aim of the primary survey is to identify and treat life-threatening problems, the early identification of a sight-threatening condition may be possible during " $\mathrm{D}$ " = disability (once " $\mathrm{A}$ ", " $\mathrm{B}$ "' and ' $\mathrm{C}$ ', have been addressed and the pupils are assessed). Although the primary reason for examining the pupils at this stage, (together with the Glasgow coma scale (GCS), is to assess any neurological disability, associated ocular findings must also be noted to help identify "visual disability". This is a convenient time rapidly to assess the visual pathway, although it is not comprehensive. Recognition of vision-threatening injuries, based simply on the history, mechanism of injury, a high index of suspicion and gross clinical findings, is all that is required at this stage, rather than detailed evaluation, which will need to be undertaken later.

\section{Airway maintenance with cervical spine protection:}

Maxillofacial trauma places the airway at risk. This risk is compounded by the common association with alcohol intoxication, and the subsequent decrease in consciousness, loss of airway reflexes and alcohol's propensity to induce vomiting $[6,7]$.

Upper airway obstruction due to maxillofacial trauma routinely results in a threatened airway. The potential associated injury to other organs and the presence of an unclear C-spine further complicates airway management. A variety of airway handling techniques are currently available. However, nothing is a fool proof and should be tailored according to a particular situation depends on the magnitude and type of the injury. Supervision of an emergency situation similar to this demands the experience and technical skills of the emergency operator and should always predict airway obstruction and be qualified enough to perform a surgical airway.

Cervical spine injury requires continuous immobilisation of the entire patient with a semi-rigid cervical collar, backboard, or tape and straps, before and during transfer to a definitive-care facility". Furthermore, sitting up will load the spine axially if the head is unsupported.

\section{Assess the patient for airway obstruction:}

Agitation suggests hypoxia, obtundation suggests hypercarbia, and cyanosis implies hypoxemia secondary to insufficient oxygenation (figure 1). Look for indication of injury to the larynx and trachea, including crepitus of the soft tissues. Clinically the patient may have stridor and tachypnea, snoring, gurgling, Hoarseness, subcutaneous emphysema, and a palpable fracture are suggestive laryngeal fracture. Check that the trachea is central.

\section{Protocol for airway management in maxillofacial trauma [8]}

- Anticipate and recognize an airway obstruction

- Clear the airway, position the patient. Perform chin lift and jaw thrust maneuver

- Confirm the nasal and oral aperture is clear then use artificial airways

- Perform bag-valve-mask ventilation. Preferably "two-person technique"

- Oroendotracheal intubation

- In unsuccessful orotracheal intubation or "cannot ventilate cannot intubate situation" perform surgical airway.

\author{
Indications of definitive airway in maxillofacial \\ injury \\ - Absent spontaneous breathing \\ - Comatose patient (glasgow coma scale <9) \\ - Airway injury or obstruction \\ - Persistent oxygen saturation $<90 \%$ \\ - High-risk for aspiration \\ - $\quad$ Systemic shock (systolic blood pressure <80) \\ - "Cannot ventilate cannot intubate" situations
}

Although evidence in literature imparts that some cervical movement is inevitable [9, 10], orotracheal intubation is comparatively safe in an unclear cervical spine. It is easier to perform, quickly and causes minimal mobilization of the cervical spine in skilled hands [11].

When noninvasive techniques for securing airway fail, the surgical airway is the only available option. They are of two types: Cricothyroidotomy and tracheostomy [12]. The cricothyrotomy is the most convenient method in emergency and can be performed by needle (needle cricothyrotomy) or by surgical scalpel (surgical cricothyrotomy) [13]. Although some schools advocates needle cricothyrotomy, its standard use is debatable.

The failure rates and insufficient oxygenation precludes it use, and surgical cricothyroidotomy is the pertinent method of choice in emergency. Tracheostomy in most of the cases is performed as an elective procedure, once the patient is stabilized by cricothyrotomy. 


Hemorrhage, massive transfusions, and
coagulopathy

The most common cause of hypotension in trauma patients is hemorrhage. Significant tissue trauma, however, adds to the hemorrhagic shock state by eliciting immunologic and inflammatory responses (14). Biomarkers of tissue ischemia or "oxygen debt" such as lactate or base deficit are useful to trend. Elevation of these variables, or failure to normalize them, is associated with increased mortality [15]. Trauma patients with severe hemorrhagic shock often require a massive transfusion, usually defined by requiring at least 10 units of packed RBCs (PRBCs) within 24 hours. The optimal fluid for resuscitation of a trauma patient in severe hemorrhagic shock would likely be whole blood. Fresh frozen plasma (FFP), platelets, and cryoprecipitate can be administered to essentially reconstitute whole blood. A ratio of $1: 1: 1$ may improve outcomes in terms of achieving hemostasis and preventing early death from exsanguination compared with higher ratios of PRBCs $[16,17]$. Small studies of banked whole blood are underway. Administration of crystalloids, colloids, or hypertonic solutions is to be minimized $[18,19]$.

Patients with active bleed should be treated with permissive atrial hypotensionand and Resuscitative Endovascular Balloon Occlusion of the Aorta for patients with abdominal or pelvic hemorrhage [20-21].

Severe hemorrhage and resuscitation causes a vicious cycle of worsening from the "lethal triad" of coagulopathy, metabolic acidosis, and hypothermia. The coagulopathy of trauma includes dilution of clotting factors, utilization of factors at the site of bleeding, intravascular coagulation, fibrinolysis, hypothermia, acidosis, inflammation, and other factors [22]. Rotational thromboelastometry may better represent overall clotting function and allow for more targeted therapy [23, 24].

Trauma patients often develop hypofibrinogenemia to control prothrombin complex concentrates are sometimes used, although data on efficacy in the absence of warfarin-induced coagulopathy are variable $(25,26)$.

Patients with hyperfibrinolysis may benefit from the use of tranexamic acid (27). With a knowledge about the coagulopathy of trauma and evidence that a more aggressive approach to normalizing hemostatic mechanisms can make progress in outcomes, the concept of damage control resuscitation has been established and recommended [28]. For the moment, point of care viscoelastic testing seems to be the best way to guide therapy [29]. Algorithm for maxillofacial trauma patient was proposed by cogbill et al is shown in (fig. 2) [30].

\section{C-Spine}

4.2-6.1\% of adults have underlying cervical spine injuries following blunt polytrauma [31, 32]. CSpine injuries occur in $1-10 \%$ of patients presenting with facial fracture(s) [33-35].

Applying a semi-rigid cervical collar allows temporary immobilization of the cervical spine providing protection from further damage until stabilization can take place [36]. To ensure maximal stabilization, these collars should be fitted snugly according to the manufacturer's guidelines. If fitted incorrectly they may precipitate airway obstruction especially in mandibular fractures [37]. In these instances it is better to apply a headbox with straps that allows greater access to the jaw and anterior neck. If a collar is to be removed, inline stabilization should be performed. Care should be taken with head injury patients as cervical collar may increase the intracranial pressure [38, 39].

Clinicians should be vigilant about C-Spine injuries and their common associations; midface injuries are associated with C5-7 disruption, whilst trauma to the lower face is more commonly associated with C1-4 disruption [40, 41].

\section{Examine the eyes for}

- Visual acuity- Can the patient count? Can patient read print?

- Restriction of eye movements, diplopia, and unequal pupillary levels.

- If one or more of these is present suspect trauma of the orbital floor and wall with entrapment of periorbital tissues.

- Direct, consensual, and accommodation reflexes. Examination of these helps to detect a rise in intracranial pressure, but be aware of false positive signs caused by trauma to the globe resulting in post-traumatic mydriasis and retrobulbar haemorrhage.

- Proptosis (or exophthalmos). This suggests haemorrhage within the orbital walls.

- Enophthalmos. This suggests fracture of the orbital wall (at the floor or medial wall).

- Periorbital swelling. If this is present suspect a fracture of the zygoma or maxilla.

- Subconjunctival ecchymosis. If this is present suspect direct trauma to the globe or a fractured zygoma.

Examine the anterior chamber and fundus for evidence of direct trauma and raised intracranial pressure.

\section{Traumatic brain injury}

Intracranial pressure (ICP) monitoring may declines rate of early mortality following severe head injury $[42,43]$. Treatment is mandatory if the threshold 
for intracranial pressure is elevated beyond $22 \mathrm{~mm} \mathrm{Hg}$ [44]. Any unexplained elevation in ICP should be evaluated by a neurologic assessment and repeat CT to rule out recurrent or worsening intracranial hemorrhage.

Management of elevated ICP was proposed on the principle of the Monro-Kellie doctrine that the intracranial space has three components: brain tissue, blood, and cerebrospinal fluid (CSF). Tiered treatment is focused toward reduction in the volume of any of these components [45].

First tier therapies usually include head of bed elevation to recover cerebral venous drainage, short acting sedation and analgesia to permit for reduction in cerebral metabolic rate, and consequent cerebral blood flow while maintaining ability to perform clinical neurologic evaluation and drainage of CSF via an external ventricular drain.

Second tier therapies include hyperosmolar therapy with either mannitol or hypertonic saline to lessen cerebral edema, mild hyperventilation inducing reflexive cerebral vasoconstriction and in some cases there are neuromuscular blockade.
Third tier therapies such as decompressive craniectomy, therapeutic hypothermia, and barbiturate coma, are controversial [46, 47-49].

Maintenance of cerebral perfusion pressure $(\mathrm{CPP}=$ mean arterial pressure - intracranial pressure $)$ has become a cornerstone of therapy in patients with head injury. The standard target CPP is $60-70 \mathrm{~mm} \mathrm{Hg}$ depending on the patients' autoregulatory status [50].

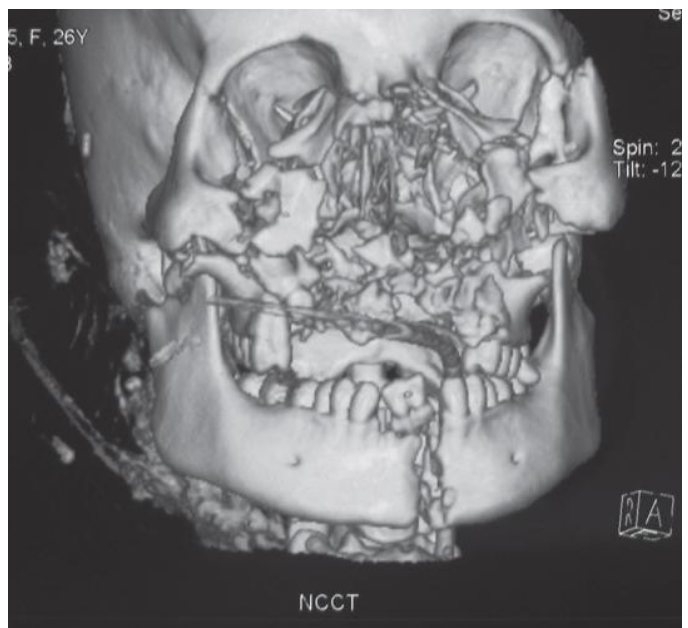

Fig-1: Airway in severely communited midface fracture can be challenging to manage

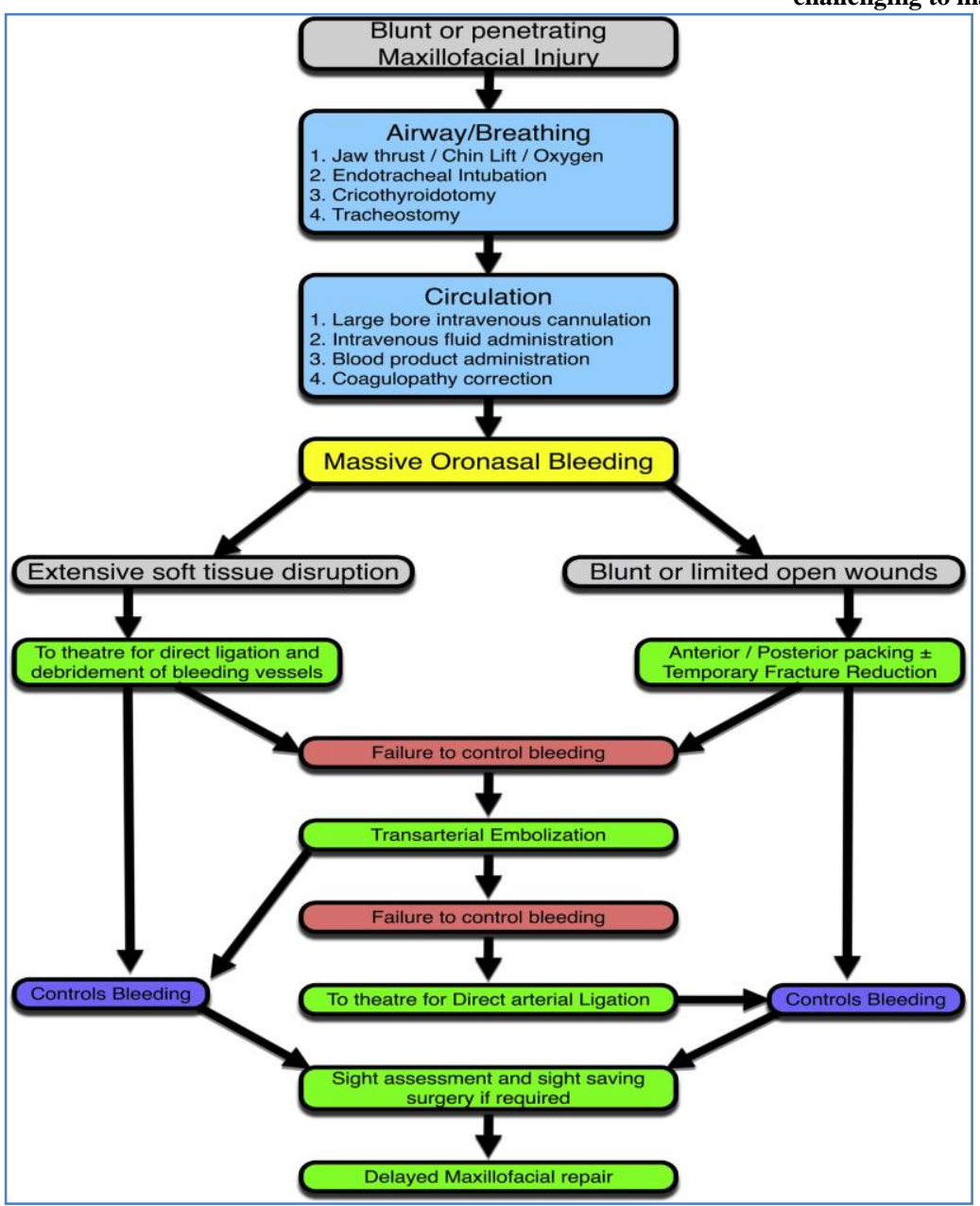

Fig-2: Proposed treatment algorithm for maxillofacial trauma as adapted from Cogbill et al.[14] 


\section{Spinal Cord Injury}

Spinal cord injury (SCI) is a particularly devastating sequel of trauma. Cervical spinal cord injuries account for over 50\% of traumatic spinal cord injuries and are related with much higher short- and long-term morbidity than injuries affecting the thoracic or lumbar cord [51]. Only little can be done for the acute primary injury to the spinal cord, the mainstay of treatment of all patients with SCI is largely supportive, focusing on minimizing secondary insults and complications.

\section{CONCLUSION}

Management of critically ill trauma patients continues to evolve, although the basic principles of rapid identification and management of life-threatening injuries remain the same. They pose problems because they are intimidating and obstruct access to the airway. Rarely, they may be the cause of life threatening haemorrhage, which is often overlooked. All the same, each case is unique; thus, the management is exacting even for the most experienced of professionals. In any given scenario no treatment approach can be described as being sure and flawless. The best outcome for these traumatised patients is associated with treatment by a multi-disciplinary trauma team, which includes a maxillofacial surgeon who has experience of these conditions.

\section{REFERENCES}

1. American College of Surgeons.(1997). Advanced Trauma Life Support Program for Doctors: ATLS. 6th ed. Chicago, IL: American College of Surgeons.

2. Alvi, A., Doherty, T., \& Lewen, G. (2003). Facial fractures and concomitant injuries in trauma patients. The Laryngoscope, 113(1), 102-106.

3. Cannell, H., Dyer, P. V., \& Paterson, A. (1996). Maxillofacial injuries in the multiply injured. European journal of emergency medicine: official journal of the European Society for Emergency Medicine, 3(1), 43-47.

4. Perry, M., Dancey, A., Mireskandari, K., Oakley, P., Davies, S., \& Cameron, M. (2005). Emergency care in facial trauma-a maxillofacial and ophthalmic perspective. Injury, 36(8), 875-896.

5. Perry, M. (2008). Advanced Trauma Life Support (ATLS) and facial trauma: can one size fit all?: Part 1: Dilemmas in the management of the multiply injured patient with coexisting facial injuries. International journal of oral and maxillofacial surgery, 37(3), 209-214.

6. Perry, M., \& Morris, C. (2008). Advanced Trauma Life Support (ATLS) and facial trauma: can one size fit all?: Part 2: ATLS, maxillofacial injuries and airway management dilemmas. International journal of oral and maxillofacial surgery, 37(4), 309-320.
7. Inder, W. J., Joyce, P. R., Wells, J. E., Evans, M. J., Ellis, M. J., Mattioll, L., \& Donald, R. A. (1995). The acute effects of oral ethanol on the hypothalamic-pituitary-adrenal axis in normal human subjects. Clinical endocrinology, 42(1), 6571.

8. Fonseca, R., Barber, H., Powers, M., Frost, D. (2012). Oral and Maxillofacial Trauma. 4th ed. St. Louis: Saunders.

9. Lennarson, P. J., Smith, D., Todd, M. M., Carras, D., Sawin, P. D., Brayton, J., ... \& Traynelis, V. C. (2000). Segmental cervical spine motion during orotracheal intubation of the intact and injured spine with and without external stabilization. Journal of Neurosurgery: Spine, 92(2), 201-206.

10. Brimacombe, J., Keller, C., Künzel, K. H., Gaber, O., Boehler, M., \& Pühringer, F. (2000). Cervical spine motion during airway management: a cinefluoroscopic study of the posteriorly destabilized third cervical vertebrae in human cadavers. Anesthesia \& Analgesia,91(5), 12741278.

11. Rhee, K. J., Green, W., Holcroft, J. W., \& Mangili, J. A. A. (1990). Oral intubation in the multiply injured patient: the risk of exacerbating spinal cord damage. Annals of emergency medicine, 19(5), 511-514.

12. Dillon, J. K., Christensen, B., Fairbanks, T., Jurkovich, G., \& Moe, K. S. (2013). The emergent surgical airway: cricothyrotomy vs tracheotomy. International journal of oral and maxillofacial surgery, 42(2), 204-208.

13. Crewdson, K., \& Lockey, D. J. (2013). Needle, knife, or device-which choice in an airway crisis?. Scandinavian journal of trauma, resuscitation and emergency medicine, 21(1), 49.

14. Tompkins, R. G. (2015). Genomics of injury: the Glue Grant experience. The journal of trauma and acute care surgery, 78(4), 671.

15. Holcomb, J. B., Del Junco, D. J., Fox, E. E., Wade, C. E., Cohen, M. J., Schreiber, M. A., ... \& Cotton, B. A. (2013). The prospective, observational, multicenter, major trauma transfusion (PROMMTT) study: comparative effectiveness of a time-varying treatment with competing risks. JAMA surgery, 148(2), 127-136.

16. Holcomb, J. B., Tilley, B. C., Baraniuk, S., Fox, E. E., Wade, C. E., Podbielski, J. M., ... \& Cohen, M. J. (2015). Transfusion of plasma, platelets, and red blood cells in a 1: 1: 1 vs a 1: 1: 2 ratio and mortality in patients with severe trauma: the PROPPR randomized clinical trial. Jama, 313(5), 471-482.

17. SAFE Study Investigators. (2004). A comparison of albumin and saline for fluid resuscitation in the intensive care unit. New England Journal of Medicine, 350(22), 2247-2256. 
18. Bulger, E. M., May, S., Kerby, J. D., Emerson, S., Stiell, I. G., Schreiber, M. A., ... \& Minei, J. P. (2011). Out-of-hospital hypertonic resuscitation after traumatic hypovolemic shock: a randomized, placebo controlled trial. Annals of surgery, 253(3), 431.

19. Brenner, M. L., Moore, L. J., DuBose, J. J., Tyson, G. H., McNutt, M. K., Albarado, R. P., ... \& Rasmussen, T. E. (2013). A clinical series of resuscitative endovascular balloon occlusion of the aorta for hemorrhage control and resuscitation. Journal of Trauma and Acute Care Surgery, 75(3), 506-511.

20. Moore, L. J., Martin, C. D., Harvin, J. A., Wade, C. E., \& Holcomb, J. B. (2016). Resuscitative endovascular balloon occlusion of the aorta for control of noncompressible truncal hemorrhage in the abdomen and pelvis. The American Journal of Surgery, 212(6), 1222-1230.

21. DuBose, J. J., Scalea, T. M., Brenner, M., Skiada, D., Inaba, K., Cannon, J., ... \& Kirkpatrick, A. (2016). The AAST prospective Aortic Occlusion for Resuscitation in Trauma and Acute Care Surgery (AORTA) registry: data on contemporary utilization and outcomes of aortic occlusion and resuscitative balloon occlusion of the aorta (REBOA). Journal of Trauma and Acute Care Surgery, 81(3), 409-419.

22. Hess, J. R., Brohi, K., Dutton, R. P., Hauser, C. J., Holcomb, J. B., Kluger, Y., ... \& Hoyt, D. B. (2008). The coagulopathy of trauma: a review of mechanisms. Journal of Trauma and Acute Care Surgery, 65(4), 748-754.

23. Holcomb, J. B., Minei, K. M., Scerbo, M. L., Radwan, Z. A., Wade, C. E., Kozar, R. A., ... \& Adams, P. R. (2012). Admission rapid thrombelastography can replace conventional coagulation tests in the emergency department: experience with 1974 consecutive trauma patients. Annals of surgery, 256(3), 476-486.

24. David, J. S., Durand, M., Levrat, A., Lefevre, M., Rugeri, L., Geay-Baillat, M. O., ... \& Bouzat, P. (2016). Correlation between laboratory coagulation testing and thromboelastometry is modified during management of trauma patients. Journal of Trauma and Acute Care Surgery, 81(2), 319-327.

25. Joseph, B., Aziz, H., Pandit, V., Hays, D., Kulvatunyou, N., Yousuf, Z., ... \& Rhee, P. (2014). Prothrombin complex concentrate versus freshfrozen plasma for reversal of coagulopathy of trauma: is there a difference?. World journal of surgery, 38(8), 1875-1881.

26. Jehan, F., Aziz, H., O'Keeffe, T., Khan, M., Hamidi, M., Zeeshan, M., ... \& Joseph, B. (2018). The role of four-factor prothrombin complex concentrate in coagulopathy of trauma: A propensity matched analysis. Journal of Trauma and Acute Care Surgery, 85(1), 18-24.

27. Williams-Johnson, J. A., McDonald, A. H., Strachan, G. G., \& Williams, E. W. (2010). Effects of tranexamic acid on death, vascular occlusive events, and blood transfusion in trauma patients with significant haemorrhage (CRASH-2): a randomised, placebo-controlled trial. West Indian Medical Journal, 59(6), 612-624.

28. Cannon, J. W., Khan, M. A., Raja, A. S., Cohen, M. J., Como, J. J., Cotton, B. A., ... \& Holcomb, J. B. (2017). Damage control resuscitation in patients with severe traumatic hemorrhage: a practice management guideline from the Eastern Association for the Surgery of Trauma. Journal of Trauma and Acute Care Surgery, 82(3), 605-617.

29. Howley, I. W., Haut, E. R., Jacobs, L., Morrison, J. J., \& Scalea, T. M. (2018). Is thromboelastography (TEG)-based resuscitation better than empirical 1: 1 transfusion?. Trauma surgery \& acute care open, 3(1), e000140.

30. Cogbill, T. H., Cothren, C. C., Ahearn, M. K., Cullinane, D. C., Kaups, K. L., Scalea, T. M., ... \& Moore, E. E. (2008). Management of maxillofacial injuries with severe oronasal hemorrhage: a multicenter perspective. Journal of Trauma and Acute Care Surgery, 65(5), 994-999.

31. Chiu, W. C., Haan, J. M., Cushing, B. M., Kramer, M. E., \& Scalea, T. M. (2001). Ligamentous injuries of the cervical spine in unreliable blunt trauma patients: incidence, evaluation, and outcome. Journal of Trauma and Acute Care Surgery, 50(3), 457-464.

32. Ross, S. E., O'Malley, K. F., DeLong, W. G., Born, C. T., \& Schwab, C. W. (1992). Clinical predictors of unstable cervical spinal injury in multiply injured patients. Injury, 23(5), 317-319.

33. Beirne, J. C., Butler, P. E., \& Brady, F. A. (1995). Cervical spine injuries in patients with facial fractures: a 1-year prospective study. International journal of oral and maxillofacial surgery, 24(1), 26-29.

34. Sinclair, D., Schwartz, M., Gruss, J., \& McLellan, B. (1988). A retrospective review of the relationship between facial fractures, head injuries, and cervical spine injuries. The Journal of emergency medicine, 6(2), 109-112.

35. Haug, R. H., Wible, R. T., Likavec, M. J., \& Conforti, P. J. (1991). Cervical spine fractures and maxillofacial trauma. Journal of oral and maxillofacial surgery, 49(7), 725-729.

36. Dupanovic, M., Fox, H., \& Kovac, A. (2010). Management of the airway in multitrauma. Current Opinion in Anesthesiology, 23(2), 276-282.

37. Perry, M., \& Morris, C. (2008). Advanced Trauma Life Support (ATLS) and facial trauma: can one size fit all?: Part 2: ATLS, maxillofacial injuries and airway management dilemmas. International journal of oral and maxillofacial surgery, 37(4), 309-320.

38. Davies, G., Deakin, C., \& Wilson, A. (1996). The effect of a rigid collar on intracranial pressure. Injury, 27(9), 647-649. 
39. Ho, A. M. H., Fung, K. Y., Joynt, G. M., Karmakar, M. K., \& Peng, Z. (2002). Rigid cervical collar and intracranial pressure of patients with severe head injury. Journal of Trauma and Acute Care Surgery, 53(6), 1185-1188.

40. Lynham, A. J., Hirst, J. P., Cosson, J. A., Chapman, P. J., \& McEniery, P. (2004). Emergency department management of maxillofacial trauma. Emergency Medicine, 16(1), 7-12.

41. Lalani, Z., \& Bonanthaya, K. M. (1997). Cervical spine injury in maxillofacial trauma. British Journal of Oral and Maxillofacial Surgery, 35(4), 243-245.

42. Griesdale, D. E., McEwen, J., Kurth, T., \& Chittock, D. R. (2010). External ventricular drains and mortality in patients with severe traumatic brain injury. Canadian Journal of Neurological Sciences, 37(1), 43-48.

43. Chesnut, R. M., Temkin, N., Carney, N., Dikmen, S., Rondina, C., Videtta, W., ... \& Machamer, J. (2012). A trial of intracranial-pressure monitoring in traumatic brain injury. New England Journal of Medicine, 367(26), 2471-2481.

44. Carney, N., Totten, A. M., O'reilly, C., Ullman, J. S., Hawryluk, G. W., Bell, M. J., ... \& Rubiano, A. M. (2017). Guidelines for the management of severe traumatic brain injury. Neurosurgery, 80(1), 6-15.

45. American College of Surgeons Trauma Quality Improvement Program: ACS TQIP Best Practices in the Management of Traumatic Brain Injury. (2015). https://www.facs.org/ /media/files/quality\%

20programs/trauma/tqip/traumatic\%20brain\%20inj ury\%20guidelines. ashx. Accessed June 6, 2018

46. Carney, N., Totten, A. M., O'reilly, C., Ullman, J. S., Hawryluk, G. W., Bell, M. J., ... \& Rubiano, A. M. (2017). Guidelines for the management of severe traumatic brain injury. Neurosurgery, $80(1)$, 6-15.

47. Cooper, D. J., Rosenfeld, J. V., Murray, L., Arabi, Y. M., Davies, A. R., D'Urso, P., ... \& Wolfe, R. (2011). Decompressive craniectomy in diffuse traumatic brain injury. New England Journal of Medicine, 364(16), 1493-1502.

48. Andrews, P. J., Sinclair, H. L., Rodriguez, A., Harris, B. A., Battison, C. G., Rhodes, J. K., \& Murray, G. D. (2015). Hypothermia for intracranial hypertension after traumatic brain injury. New England Journal of Medicine, 373(25), 2403-2412.

49. Alnemari, A. M., Krafcik, B. M., Mansour, T. R., \& Gaudin, D. (2017). A comparison of pharmacologic therapeutic agents used for the reduction of intracranial pressure after traumatic brain injury. World neurosurgery, 106, 509-528.

50. Johnson, U., Nilsson, P., Ronne-Engström, E., Howells, T., \& Enblad, P. (2011). Favorable outcome in traumatic brain injury patients with impaired cerebral pressure autoregulation when treated at low cerebral perfusion pressure levels. Neurosurgery, 68(3), 714-722.

51. DeVivo, M. J., \& Ivie III, C. S. (1995). Life expectancy of ventilator-dependent persons with spinal cord injuries. Chest, 108(1), 226-232. 